\title{
The quality of care in family planning services: an assessment of family welfare centres in Gujranwala, Pakistan
}

\author{
Shazia Yasmin 1 , Jaleel Miyan ${ }^{1}$ \\ ${ }^{1}$ Faculty of Biology, Medicine \& Health, The University of Manchester, Manchester, UK \\ Keywords: global health \\ https://doi.org/10.29392/joghr.2.e2018027
}

\section{Journal of Global Health Reports}

Vol. 2, 2018

\begin{abstract}
Background
To assess the quality of provision, the present study assessed ten core needs of clients attending family planning services including information, access, choice, safety, privacy, confidentiality, dignity, comfort and continuity of care as well as the opinion of clients on the service provision.
\end{abstract}

\section{Methods}

In this study 11 Family Welfare Centres (FWCs) were selected proportionally from total 51 FWCs and this study was carried out in the Gujranwala district of Punjab, Pakistan. A sample of size of 600 married women, aged 15-45 years was selected with at least one surviving child and these women were using any contraceptive method. Quantitative analysis was performed to identify links between needs and quality of care.

\begin{abstract}
Results
Significant weaknesses in addressing the needs of clients were identified. $55.8 \%$ of clients were not informed how to use different contraceptive methods while $62.5 \%$, due to low economic status, could not afford to choose any but the cheapest methods so were unable to access the full range and potentially more appropriate methods for them. $63.5 \%$ were not given the method of their own choice and $63 \%$ were not counselled about the management of side-effects. 51\% said they were counselled in the presence of other clients and 59\% were not informed about follow-up visits. Overall 51.2\% of respondents rated quality of care poor in terms of their satisfaction.
\end{abstract}

\section{Conclusions}

Any family planning program should focus on the needs of clients not numbers seen to achieve their targets. More attention should be given to filling the gaps in needs of clients with a better provision of information and choice as well as continuity of care.

Providing good quality means "doing the right things right”. A family planning (FP) program of high quality should be one that is client oriented and aims to help individuals to achieve their reproductive intentions or goals. ${ }^{1}$ To this end Bruce introduced a six element model for the quality of care in any family planning service delivery program involving: i. choice of methods, ii. information given to clients, iii. technical competence of providers, iv. interpersonal relations, v. mechanisms to encourage continuity, and vi. an appropriate range of services. ${ }^{2}$ This model also provides a valuable framework to assess the quality of care actually available. ${ }^{3}$ These issues are global in nature and the variability in service provision is variable at both national and international levels with poor and deprived areas of even the developed nations suffering poor quality provision.

A recent total population estimate for Pakistan was 207.7 million with an annual growth rate of $2.40 \%$ between 1998 and 2017. ${ }^{4}$ Increasing population has serious consequences to overcrowded urban areas, food security and environmental problems, not to mention all the support services underpinning society. ${ }^{5}$ Population control has become an increasingly important aspect of human society. Pakistan reports the prevalence of contraceptive use at $35.4 \%$ whereas a population control program has remained an important policy issue since 1960 . With the desired results failing to be achieved, there is a pressing need to focus on family planning services and the individual needs of women with differing socio-demographic characteristics to identify the issues at fault. ${ }^{6}$ Many studies highlight the fact that success in FP programs requires a high quality of family planning service provision which is essential for approval, satisfaction and continued use. Family planning services must be client-centred, available and equitable for clients. Service providers should therefore have access to high quality training programs, including counselling practices of 
nurses, which will result in improved client satisfaction with FP services. 7,8

In focus group discussions with women Keesara et $\mathrm{al}^{9}$ found that the selection of private family planning clinics over public clinics was due to a better availability of medications and contraceptives, no waiting time, provision of a desired FP method rather than a single option, respectful treatment, confidentiality, competency of staff and patient safety. However, public health centres play an important role for provision of family planning services in deprived/ rural communities but clearly need additional direct funds, technical assistance and active health promotion programs to improve FP service quality as a fundamental part of care and thereby increase the take-up. ${ }^{10-14}$ Burior and Zafar ${ }^{15}$ found that $71 \%$ of Government centres did not have the basic medicines supply system working properly due to shortages of funds, $82 \%$ of managers reported a lack of important medicines and $67 \%$ of clients were dropping out due to poor management of side-effects of contraceptives and medicines. Significantly $62 \%$ of managers had had no training in the previous two years related to this study. ${ }^{15}$ With every family planning and reproductive health program in the world focusing its attention on quality, there has been a shift in emphasis from quantity to quality as this is the main driver for clients to take up the service provision. The major objective of the current investigation is thus to explore the elements of the quality of care in family planning services in Punjab, Pakistan focussing on the needs of clients and whether these are met. We believe the findings will be applicable to areas of low socioeconomic and deprived areas anywhere in the world as these tend to be neglected in provision of quality services.

\section{MATERIAL AND METHODS}

The present investigation was conducted at health centres in district Gujranwala, Punjab province of Pakistan. The Ministry of Population Welfare in Pakistan has a network of Family Welfare Centres (FWCs) operating in the Punjab province. These Government centres have a close similarity with each other so that the data collected should be generally applicable to all. The study area covered both urban and rural areas of district Gujranwala and we selected 11 of 51 total FWCs (20\%) from all four tehsils: Gujranwala, ${ }^{5}$ Kamoke, ${ }^{2}$ Nowshera Virkan ${ }^{1}$ and Wazirabad Tehsil. ${ }^{3}$ The selected FWCs comprised of six rural and five urban locations. Clients from each FWC were selected to give a total sample size for the study of 600 married women having at least one surviving child and who were using any contraceptive method.

The interviewed women clients were those who went to the FWCs for family planning related services, whether they were new visitors or return visitors on the day of interview. Verbal interviews were carried out by the researcher on site, at the exit point, as most women could not read or write. The data were collected by using a structured interview schedule and analysed using descriptive and inferential statistical techniques. Regression analysis was preformed to identify the relative importance of each of the independent explanatory variables (client needs) in terms of explained variation in the dependent response variable (re-
Table 1. Distribution of respondents on the basis of background characteristics $(\mathrm{N}=600)$

\begin{tabular}{|c|c|}
\hline Background characteristics & Percentage \\
\hline \multicolumn{2}{|l|}{ Place of residence: } \\
\hline Urban & 45.0 \\
\hline Rural & 55.0 \\
\hline \multicolumn{2}{|l|}{ Age categories (in years): } \\
\hline $15-20$ & 4.5 \\
\hline $21-25$ & 20.0 \\
\hline $26-30$ & 29.0 \\
\hline $31-35$ & 21.0 \\
\hline $36-40$ & 22.0 \\
\hline $41-45$ & 3.5 \\
\hline \multicolumn{2}{|l|}{ Education: } \\
\hline Illiterate & 34.8 \\
\hline Primary & 21.8 \\
\hline Middle & 20.7 \\
\hline$E$ & 18.7 \\
\hline Secondary* & 3.5 \\
\hline Graduate + & 0.5 \\
\hline \multicolumn{2}{|l|}{ Monthly family income (Rupees): } \\
\hline Up to 5000 (US\$ 41) & 55.5 \\
\hline 5001-7500 (US\$ 41 - US\$ 62) & 39.6 \\
\hline $7501+$ above (US\$ $62+$ ) & 25.4 \\
\hline
\end{tabular}

*Matric/GCSE - Age 15 O-levels or General Certificate of Secondary Education

ceived quality of care in terms of satisfaction with needs). Multiple linear regression analysis was used and two measures, regression coefficient beta and coefficient of determination $\left(\mathrm{R}^{2}\right)$ were used to establish the importance of each of the variables in the model.

\section{RESULTS}

In this investigation we focused on ten core client needs including information, access, choice, safety, privacy, confidentiality, dignity, comfort, continuity of care, opinion concerning provision of family planning services.

\section{SOCIO-ECONOMIC CHARACTERISTICS OF CLIENTS}

The clients included in this study came from both rural (55.0\%) and urban (45.0\%) areas and had the socio-economic characteristics listed in Table 1 . The age range distribution of respondents was $29 \%$ between $26-30$ years, $22 \%$ between $36-40$ years and $21 \%$ between $31-35$ years. Literacy rates were also variable with a distribution across illiterate $34.8 \%$, primary $21.8 \%$, middle education $20.7 \%$, matric $18.7 \%$, intermediate $3.5 \%$ and graduate or above level $0.5 \%$. More than half the respondents belonged to the labour class and most had low household incomes ranging from only up to 5000 Pak Rupees (US\$39, 55.5\%), 5000 -7500 Pak Rupees (US\$39-58, 33\%) and with only $9.8 \%$ having more than 7501 Pak Rupees (US\$58) per month family income. 


\section{ASSESSMENT OF NEEDS}

The results of assessment of client needs are shown in Table 2. During their first visits to FWCs, $55.5 \%$ were not informed about all methods of contraception, $52.3 \%$ were not provided information about the merits of different family planning (FP) methods, $54.3 \%$ were not informed about the side effects of contraceptive methods and $55.8 \%$ did not have the use of family planning methods clearly explained. According to $62.5 \%$ of respondents service providers did not inform them about any side-effects and $63 \%$ were not counselled about how to manage any side effects. Counselling in the presence of other clients was experienced by $51.0 \%$ respondents with only $50.7 \%$ reporting privacy during physical examinations. Not getting the FP method of their own choice was reported by $63.6 \%$ of respondents and more than half the respondents $(55.5 \%)$ reported that service providers selected the FP method for them which was reflected in $50.3 \%$ reporting that their family planning method was not according to their personal reproductive intentions. Access to FWCs was reported as difficult by $60.2 \%$ of respondents while $62.5 \%$ respondents could not afford the fees charged with $67.0 \%$ reporting that they were charged fees when they visited these centres. Service providers assured only $43.3 \%$ of respondents that their personal information would be kept confidential and 53.2\% also said they were not treated with any respect. $72.2 \%$ of respondents reported that the waiting area was not comfortable with $69.7 \%$ reporting no good seating facilities. We also found additional weaknesses in the needs of continuity of care as $59 \%$ of respondents were not told about follow up visits and $53.2 \%$ of respondents reported that their own wishes and opinion were ignored during their visit to the centre. When asked to rate the quality of care at FWCs in terms of satisfaction with their needs, $51.2 \%$ of respondents rated the service as poor, $26.5 \%$ average and only $22.3 \%$ as good quality of care (Table 3).

\section{REGRESSION ANALYSIS}

In order to examine the relative significance of the different variables measured in this study in explaining the response variable, satisfaction as perceived quality of care, we carried out multiple regression analysis of the data using SPSS software v19.0 (IBM, Armonk, NY, USA). Table 4 presents unstandardized and standardized regression coefficients of every predictive variable along with the standard error and significance level for each relative to the response variable. These values were generated by the SPSS comparing the regression coefficient to the null hypothesis that there is no effect of the variable on the measure of satisfaction of perceived quality of care. Significance $(P \leqslant 0.05$ significant at $95 \%$ confidence level or $P \leqslant 0.01$ significant at $99 \%$ confidence) indicates that the variable has a direct bearing on satisfaction in perceived quality of care. The data show that the needs of safety, choice, information, privacy and confidentiality are the most important determinants of quality of care with regression coefficients of $0.181,0.173,0.172$, 0.169 and 0.168 respectively with all significant at $99 \%$. The other independent variables of access, dignity, comfort, family income, continuity of care education and expression of opinion, were also important predictor variables in explaining the quality of care with regression coefficients of $0.161,0.156,0.135,0.129,0.1160 .106$ and 0.096 respectively and with significance at $0.002,0.001,0.005,0.001$, $0.003,0.015$ and 0.012 respectively. The fitness of the model, ie, the importance of the measured variable to explain the response variable of perceived quality of care, is examined through the coefficient of multiple correlations, that is R2. The value of R2, generated as part of multiple regression analysis in SPSS, in our analysis was 0.48 for the variables found to have significant correlations to perceived quality of care, and indicates that the independent variables of education, family income, need for information, access, choice, safety, privacy, confidentiality dignity comfort, continuity of care and opinion explained $48 \%$ of the variation in quality of care received by respondents. Educational status of clients significantly linked with quality of care with increasing higher education correlating with greater satisfaction with quality of FP largely through better knowledge of what is available and personal planning.

\section{DISCUSSION}

Health centres play an important role for provision of family planning services throughout the world and are particularly important in deprived communities where they clearly need additional direct funds, technical assistance and active health promotion programs to improve FP service quality as a fundamental part of care. ${ }^{10}$

\section{INTERPRETATION}

The women surveyed in the current study were aged between 15 and 45 years old covering the majority range for reproductive age. All of these women were using contraceptive methods but across the population, other studies show that the use of any contraceptive method was only $35.4 \%$ among all married women aged 15-19 and 51.2\% among married women who did not want more children [6). Together these findings indicate poor provision and/or quality of family planning service as the contraceptive adoption rate is very low even though women desire a certain family size. Such a situation may be indicative of deprived areas anywhere, even in developed countries where family planning and family welfare centres, and/or easy access to such provision is difficult or missing. However, in Pakistan, unlike developed countries, $42 \%$ of people cannot read or write, $57 \%$ of ever-married women age 15-49 have never attended school, $16 \%$ only have primary education, $7 \%$ only up to middle, $10 \%$ had some secondary education (class 9-10), and only $9 \%$ reached class 11 or higher. ${ }^{5,6}$ We also found a low level of literacy in the women surveyed in the present study which acts as a retarding force for development, ${ }^{16}$ while higher education influences family formation and positive socioeconomic development, as well as a better knowledge of, and satisfaction with family planning services through a better understanding of what was available and what they need. ${ }^{17,18}$ In our study more than half the respondents were from the labour class with $55.5 \%$ only earning up to 5000 Pak Rupees (about US\$41) per month in family income. This is a very low income level but is in line 
Table 2. Assessment of clients' needs

\begin{tabular}{|c|c|c|c|}
\hline Information & Yes & No & Don't know or No response \\
\hline All types of contraceptive methods explained during first visit & 39.2 & 55.5 & 5.3 \\
\hline The merits of different contraceptive methods explained & 43.9 & 52.3 & 3.8 \\
\hline Side effects of each contraceptive method explained & 25.0 & 54.3 & 20.7 \\
\hline How to use each method & 38.7 & 55.8 & 5.5 \\
\hline \multicolumn{4}{|l|}{ Access: } \\
\hline Easy access from home to Family Welfare Centre & 39.7 & 60.2 & 1.2 \\
\hline Affordability of fees & 37.0 & 62.5 & 0.5 \\
\hline Provision of free service & 24.5 & 67.0 & 8.5 \\
\hline \multicolumn{4}{|l|}{ Choice: } \\
\hline Method of own choice & 34.2 & 63.6 & 2.2 \\
\hline Selection of FP method & 55.5 & 41.7 & 2.8 \\
\hline FP method according to reproductive intention & 22.7 & 50.3 & 27.0 \\
\hline \multicolumn{4}{|l|}{ Safety: } \\
\hline Explanation of side effects & 31.8 & 62.5 & 5.7 \\
\hline Management of side effects & 26.7 & 63.0 & 10.3 \\
\hline \multicolumn{4}{|l|}{ Privacy: } \\
\hline Privacy during counselling/consultation & 38.3 & 51.0 & 10.7 \\
\hline Privacy during physical examination & 50.7 & 32.2 & 17.1 \\
\hline \multicolumn{4}{|l|}{ Confidentiality: } \\
\hline Confidentiality of all personal information & 43.3 & 21.5 & 35.2 \\
\hline \multicolumn{4}{|l|}{ Dignity: } \\
\hline Treated with respect & 39.0 & 53.2 & 7.8 \\
\hline \multicolumn{4}{|l|}{ Comfort: } \\
\hline Waiting area was comfortable & 21.8 & 72.2 & 6.0 \\
\hline Good and sufficient seating facilities & 21.5 & 69.7 & 8.8 \\
\hline \multicolumn{4}{|l|}{ Continuity of care: } \\
\hline Follow up visit & 35.7 & 59.0 & 5.3 \\
\hline \multicolumn{4}{|l|}{ Right to opinion: } \\
\hline Feedback about quality of service & 20.5 & 53.2 & 26.3 \\
\hline
\end{tabular}

FP - family planning

Table 3. Quality of care rating by respondents in terms of satisfaction with services

\begin{tabular}{lc}
\hline The quality of care & Received care (\%) \\
\hline Poor & 51.2 \\
Average & 26.5 \\
Good & 22.3 \\
Total & 100.0 \\
\hline
\end{tabular}

with the findings of other similar studies in which $54.16 \%$ of respondents had poor family income. ${ }^{19}$ None of the interviewed women had easy, or any access to the internet since this was too expensive for their income. They also had no access to internet cafes or other networking centres.

Our current study found weaknesses in the information provision process, such that clients on their first visits were not getting an explanation of all available contraceptive methods, the merits of different methods, side effects, or clear answers to their own questions and worries similar to findings in other studies and in other countries. ${ }^{20-22}$ We also found that the majority of respondents did not have easy physical access to centres and could not afford the fee charges. Siting FWCs in proximity to residential areas and costs charged to get FP advice and services are strong influencers in the accessibility of services ${ }^{23}$ so that these must be serious factors in any National strategy to enhance service provision.

Our findings expose serious deficiencies in choice and safety needs of clients in the provision of family planning services at Family Welfare Centres in the areas of Punjab we carried out our surveys. In addition to difficulty to access centres and costs, respondents were not getting good, respectful advice or methods fitting their preferences and family planning objectives. Service providers were selecting FP method for most of clients without discussion of options reflecting findings in other studies in which only $22 \%$ of the clients received all of the family planning service items on a check list. ${ }^{17}$ We also found that the side effects of FP methods provided were not discussed with clients and 
Table 4. Multiple regression model with quality of care (satisfaction with rights) as dependent variable*

\begin{tabular}{|c|c|c|c|c|}
\hline \multirow{2}{*}{ Variable } & \multicolumn{2}{|c|}{ Un-standardized coefficients } & \multicolumn{2}{|c|}{ Standardized coefficients } \\
\hline & B & Standard Error & $\beta$ & Significance level \\
\hline Education & 0.125 & 0.028 & $0.106 \dagger$ & 0.015 \\
\hline Family income & 0.138 & 0.043 & $0.129 \dagger$ & 0.001 \\
\hline Information & 0.187 & 0.051 & $0.172 \ddagger$ & 0.023 \\
\hline Access & 0.167 & 0.045 & $0.161 \dagger$ & 0.002 \\
\hline Choice & 0.314 & 0.069 & $0.173+$ & 0.001 \\
\hline Safety & 0.192 & 0.043 & $0.181 \dagger$ & 0.001 \\
\hline Privacy & 0.189 & 0.051 & $0.169 \ddagger$ & 0.002 \\
\hline Confidentiality & 0.175 & 0.047 & $0.168 \dagger$ & 0.001 \\
\hline Dignity & 0.160 & 0.062 & $0.156 \dagger$ & 0.001 \\
\hline Comfort & 0.140 & 0.042 & $0.135 \dagger$ & 0.005 \\
\hline Continuity of care & 0.213 & 0.071 & $0.116 \dagger$ & 0.003 \\
\hline Opinion & 0.141 & 0.056 & $0.096 \ddagger$ & 0.012 \\
\hline
\end{tabular}

${ }^{*} \mathrm{R}^{2}=0.48$.

†Significant at $1 \%$.

$\ddagger$ Significant at $5 \%$.

this presents a major and serious weakness in addressing the safety needs of respondents in service provision. This was the case for all all family planning methods provided and $63 \%$ respondents reported that they were not informed about management of side effects which can be severe ${ }^{24}$ and may be related to the technical competency of service providers. ${ }^{24,25}$ In addition, service providers provided counselling in the presence of other clients and not all clients had any privacy for physical examinations. Counselling two clients simultaneously was not uncommon and, aside from lack of privacy to the individual, this also presented a major barrier for male partners to attend family planning services. ${ }^{12}$ Demonstrated commitment to confidentiality and privacy are key indicators of inclusion, client confidence and satisfaction with FP services. ${ }^{9,22-24}$ Significantly, $44.7 \%$ of our respondents reported that they were not treated with any respect and that the waiting area was not comfortable and had poor seating facilities even though these factors are essential for user confidence and use. ${ }^{9}$ Most of our respondents were also not informed about follow up visits and many were not asked to give any feedback. The views and voices of clients are central to improve the quality of services but often neglected in family planning programmes. ${ }^{26}$ In consequence the majority of respondents rated the service provision as poor in contrast to other countries where other issues were raised.9,18 Pakistan thus falls below expected and acceptable standards for this important healthcare provision.

Multiple regression analysis of our data indicated that the independent variables of education, family income, need to information, access, choice, safety, privacy, confidentiality dignity comfort, continuity of care and opinion explained $48 \%$ of the variation in quality of care received by respondents. Educational status of clients was also significantly linked with quality of care and satisfaction with quality of FP although different studies have found the opposite. ${ }^{22}$ Other studies have correlated the technical competency of service providers $15,23-26$ with client satisfaction.
Clients of private clinics are usually more satisfied than those attending public clinics ${ }^{27,28}$ presumably due to the quality or provision being driven by commercial incentives.

\section{STRENGTHS AND WEAKNESSES}

This study recruited a large population of women attending rural and urban health centres. All women interviewed were attending for family planning advice and services. The study did not interview any women who did not come to the health centres so that investigations of why this population of women did not use the service provision remain to be carried out. A general survey of women in the population would also be useful to establish why there is so little use of family planning services. Also, although the urban centres were within the city of Gujranwala, it would be interesting to contrast these with similar centres in the larger, more metropolitan and cosmopolitan city of Lahore for example. In such a location we would expect much better knowledge of contraception, the different methods available as well as to information on good service providers through better information availability, not least through access to the internet. In addition we would likely include women who choose not to have children against the cultural norm where pregnancy is expected soon after marriage. A follow on study should also look at the situation of the service providers in terms of their abilities to provide adequate, good quality service and care. This would need to include supply lines for literature, materials, drugs and devices to provide all methods of FP as well as training and qualifications to identify the weaknesses up the chain from the service providers themselves. This would then give a comprehensive picture of how to improve service provision.

\section{CONCLUSIONS AND RECOMMENDATIONS}

The present study has exposed a poor quality of family planning service provision in the study areas. Many short- 
comings in addressing the needs of clients were evident in the data and these may be due to the fact that most service providers were being pressured to achieve targets with little emphasis on quality of service provision. However, in the long term, one cannot be achieved without the other so that there is an urgent need to provide best quality services focusing on the needs of people not the numbers seen in order to achieve real progress in family planning and population control. The test of a good service would be independence from the variables highlighted in this study that determine client satisfaction. We believe that the findings of this study are generally applicable to service provision in areas of deprivation, low socioeconomic and educational status and where knowledge and practice of family planning is low. Such locations are in every developed as well as developing country and thus our findings should be useful to all bodies involved in planning and delivering these services.

\section{ACKNOWLEDGEMENTS}

We thank the Population Welfare Department, Government of Punjab for permission to carry out this study as well as the staff of the family welfare centres, in particular Samina Saleem, who helped in facilitating this study.

\section{FUNDING}

None.

\section{COMPETING INTERESTS}

The authors have completed the Unified Competing Interest form at http://www.icmje.org/coi_disclosure.pdf (available on request from the corresponding author), and declare no conflict of interest.

\section{CORRESPONDENCE TO:}

\section{Dr Shazia Yasmin}

Visiting Scientist (c/o Miyan)

Faculty of Biology, Medicine \& Health

The University of Manchester

3.540 Stopford Building

Oxford Road

Manchester M13 9PT

UK

Shazia.Yasmin@manchester.ac.uk 


\section{REFERENCES}

1. Jain A, Bruce J, Mensch B. Setting standards of quality in family planning programs. Stud Fam Plann. 1992;23(6):392-395. doi:10.2307/1966897

2. Bruce J. Fundamental elements of quality of the care: A simple framework. Stud Fam Plann. 1990;21(2):61-91. doi:10.2307/1966669

3. RamaRao S, Mohanam R. The quality of family planning programs: concepts, measurements, interventions and effects. Stud Fam Plann. 2003;34(4):227-248. doi:10.1111/j.1728-4465.2003.00 227.x

4. Federal Bureau of Statistics. Provisional Summary Results of 6th Population and Housing Census. Islamabad, Pakistan; 2017.

5. Pakistan Economic Survey 2016-17. Government of Pakistan. Economic Advisor Wing, Finance Division; 2017.

6. Pakistan Demographic and Health Survey, (2012-13). National Institute of Population Studies, MEASURE DHS. ICF International; 2013.

7. Williams JR, Gavin LE, Carter MW, Glass E. Client and provider perspectives on quality of care a systematic review. Am J Prev Med. 2015;49(2):S93-106. doi:10.1016/i.amepre.2015.03.01 7

8. Nasr E, Hassan H. Association between quality of family planning services and client's satisfaction level in maternal and child health centers in Port Said city. J Nurs Educ Pract. 2016;6:85-99.

9. Keesara SR, Juma PA, Harper CC. Why do women choose private over public facilities for family planning services? A qualitative study of post-partum women in an informal urban settlement in Kenya. BMC Health Serv Res. 2015;15(1):335-345. doi:10.118 6/s12913-015-0997-7

10. Goldberg DG, Wood SF, Johnson K, et al. The organization and delivery of family planning Services in community health centers. Womens Health Issues. 2015;25(3):202-208. doi:10.1016/i.whi.2015.02.007

11. Tessema GA, Gomersall JS, Mahmood MA, Laurence CO. Factors determining quality of care in family planning services in Africa: A systematic review of mixed evidence. PLoS One. 2016;11(3):e0165627. doi:10.1371/journal.pone.01656 $\underline{27}$
12. Simbar M, Ahmadi M, Ahmadi G, Majd HRA. Quality assessment of family planning services in urban health centers of Shahid Beheshti Medical Science University, 2004. Int J Health Care Qual Assur Inc Leadersh Health Serv. 2006;19(5):430-442. doi:10.1 $\underline{108 / 09526860610680076}$

13. Tafese F, Woldie M, Megerssa B. Quality of family planning services in primary health centers of Jimma zone, Southwest Ethiopia. Ethiop J Health Sci. 2013;23:245-254. doi:10.4314/ejhs.v23i3.7

14. Malik FR. Quality family planning services provision at private clinics of Khyber Pakhtunkhwa province, Pakistan. Gomal J Med Sci. 2015;13:171-182.

15. Burior AA, Zafar R. Evaluation and Assessment of QOC at FWC (2010-11). National Institute of Population Studies; 2012.

16. Bhatti FA, Munir D, Afsar U. Accelerating fertility transition in Pakistan: A benchmarking analysis for South Asia. In: Population Research and Policy Development in Pakistan: Fourth Conference Proceedings. December 9-11, 2003. Population Association of Pakistan; 2004.

17. Shahidzadeh-Mahani A, Omidvari S, Baradaran HR, Azin SA. Factors affecting quality of care in family planning clinics: A study from Iran. Int J Qual Health Care. 2008;20(4):284-290. doi:10.1093/intahc/ $\underline{\text { mzn016 }}$

18. Agha S. Is low income a constraint to contraceptive use among the Pakistani poor? J Biosoc Sci. 2000;32(2):161-175. doi:10.1017/s0021932000001 $\underline{619}$

19. Nasr E, Hassan H. Association between quality of family planning services and client's satisfaction level in maternal and child health centers in Port Said city. J Nurs Educ Pract. 2016;6:85-99.

20. Assaf S, Wang W, Mallick L. Quality of care in family planning services in Senegal and their outcomes. BMC Health Serv Res. 2017;17(1):346-361. doi:10.1186/s12913-017-2287-z

21. Yasmeen F, Shami N. Emergency contraception; knowledge and attitude of family physican of a teaching hospital, Lahore. Prof Med J. 2012;19:251-258. 
22. Kim YM, Silva D, Rinehart W, et al. Promoting informed choice: Evaluation a decision-making tool for family planning clients and providers in Mexico. Int Fam Plan Perspect. 2005;31(4):162-171. doi:10.136 3/3116205

23. Tessema GA, Gomersall JS, Mahmood MA, Laurence $\mathrm{CO}$. Factors determining quality of care in family planning services in Africa: A systematic review of mixed evidence. PLoS One.

2016;11(11):e0165627. doi:10.1371/journal.pone.0165 $\underline{627}$

24. Kumar S, Priyadarshni A, Kant S, Anand K, Yadav BK. Attitude of women towards family planning methods and its study from a slum of Delhi. Kathmandu Univ Med J. 2005;3:259-262.

25. Agha S, Do M. The quality of family planning services and client satisfaction in the public and private sectors in Kenya. Int J Qual Health Care. 2009;21(2):87-96. doi:10.1093/intqhc/mzp002
26. Tsegaye GA, Kifle WH, Sena BK. Clients satisfaction with family planning services and associated factors among family planning users in Hossana Town Public Health Facilities, South Ethiopia: Facility-based cross-sectional study. Int $J$ Nurs Midwifery. 2015;7(5):74-83. doi:10.5897/ijnm201 5.0163

27. Schuler SR, Hossain Z. Family planning clinics through women eyes and voices: A case study from rural Bangladesh. Int Perspect Sex Reprod Health. 1998;24(4):170-175. doi:10.2307/2991975

28. Hutchinson PL, Do M, Agha S. Measuring client satisfaction and the quality of family planning services: a comparative analysis of public and private health facilities in Tanzania, Kenya and Ghana. BMC Health Serv Res. 2011;11(1):203-217. doi:10.1186/147 2-6963-11-203 